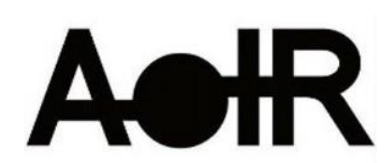

Selected Papers of \#AoIR2021:

The 22nd Annual Conference of the

Association of Internet Researchers

Virtual Event / 13-16 Oct 2021

\title{
AUTHENTIFICATION AT THE EDGE: \#"GAMERGATE"-ING THE ASCENT OF THE VERIFIED INTERNET
}

\author{
Nelanthi Hewa \\ University of Toronto \\ Christine H. Tran \\ University of Toronto
}

\section{Introduction}

For multi-platformed creators-be they writers, game streamers, or pornographers-success begins with neither the gaming of algorithms nor policy changes. Rather, it begins with the "gaming" of authenticity and its affordances: building units of affinity between yourself and audiences that feel "real" enough to see returns in followers, subscriptions, and other monetized metrics of reputation. From "verified accounts" to "two-factor authentication," platform affordances have proffered metrics of "authenticity" as an antidote to concerns about online dangers, identity theft, or general duplicity. Yet recent events have also demonstrated that the platformization of these realness claims may be weaponized against marginalized users, as illustrated by PornHub's purge of unverified accounts (Caplan, 2020).

Building on recent studies of authenticity cultures and digital branding (Abidin, 2016; BanetWeiser, 2012; Duffy, 2017; Marwick 2013), we historicize this widespread labour of realnessmaking within the framework of a hashtag event that transformed online cultures of realness, legitimacy, and professional authentication: \#GamerGate. In 2014, \#Gamergate became a vector by which primarily female journalists and media critics, as well as video game developers, were targeted and harassed. Proponents accused feminists of "collusion" with the video game industry and journalists. \#GamerGate began in earnest when video game developer Zoë Quinn was falsely accused of sleeping with a Kotaku journalist in exchange for positive coverage of their game, Depression Quest.

We analyze "GamerGate" as a pivotal moment in the platform veracity ecosystem when influencers, journalists, and users alike were exhorted to authenticate their lives or lose their livelihoods (Gray et al., 2017). This paper revisits the historic disciplining of realness via the ascent of verification tools, which permeate the contemporary platform creator economies. Indeed, we argue that \#GamerGate illuminates how journalists exist not as separate from digital influencers but as one node in a network of digital labourers. The rise of digital disclosure agreements about the "transparency" between creators and community, we argue, downloaded realness from a social project to a software problem. Notions of journalistic "objectivity"-

Suggested Citation (APA): Hewa, N., and Tran, C., (2021, October). Authentification at the Edge: \#"Gamergate"-ing the Ascent of the Verified Internet. Paper presented at AolR 2021: The 22nd Annual Conference of the Association of Internet Researchers. Virtual Event: AolR. Retrieved from http://spir.aoir.org. 
already contested and fraught—came to be replaced by flexible, always gendered and raced notions of authenticity and "realness."

We argue that, in 2014, the standards of verification-as-labour matured as digital publications responded to GamerGate by redistributing the onus of self-verifying onto journalists. Kotaku, Polygon and other media companies shifted their policies to make it mandatory that their journalists disclose financial support they had given to games' crowdfunding efforts, among other changes (VanDerWeff, 2014). Such policies, we assert, are part of digital-native outlets' attempt to establish "trustworthiness" and "objectivity" in journalists who are caught in a doublebind. Contemporary journalists and influencers are responsibilized to build their own brands while depending on Kotaku, Twitch, or Twitter for mechanisms to prove their authenticity through disclosure agreements or blue checks.

\section{Methodology}

We conduct a Critical Discourse Analysis of 30 to 40 contemporary news stories related to \#GamerGate from 2014 and 2015 to examine the gendered and racialized work that gaming journalists were compelled to perform to produce their legitimacy in the wake of targeted harassment campaigns. Questions of realness, journalistic objectivity, and authenticity motivate this coding. Guided by Potter's (1996) technique for examining how discursive statements perform "reality," we attend to the way that ideologies of "realness" shift and morph along gendered and racialized lines, with veracity being easily within the grasp of certain bodies while proving elusive to others (Duffy, 2021). We will do thematic coding (Braun \& Clarke, 2008) using qualitative coding software Dedoose, which is useful for collaborative qualitative research.

We pair this thematic coding with a CDA of authentification and verification measures expressed in the policies and public discourse of platforms such as PornHub and Twitter in 2020. We undertake this to illustrate an ideological continuity between the ostensibly separate moments of \#GamerGate and platform verification and demonstrate the cultural rise of "authentification-assafety."

\section{Contributions}

We argue that work contributes to scholarship that puts pressure on the synonymizing of "safety" and "veracity" in platform discourse, as well as notions of authenticity online more broadly. As André Brock Jr. (2015) has argued, notions of online identity as somehow inauthentic when compared to offline identities continue to hold sway; however, for racialized people and other minoritized groups, identity is always a performed self and one is "rarely considered authentic" (p. 1087). We thus work to recontextualize the meaning of digitally mediated realness by considering how platform affordances are fundamentally implicated in the work of users to appear "real."

Finally, our work reframes the digital (pre)history of entrepreneurial journalism. The social imaginary of the journalist as a self-regulating individual is a figure who, Cohen (2015) argues, "too willingly embraces a model of media production in which financial risk and responsibility for journalism's future are offloaded onto individuals" (p. 517). As journalists continue to be pushed to be both providers of news and digital influencers (Lorenz, 2020), we explore how these dynamics affect(ed) racialized and minoritized journalists during \#GamerGate and beyond (Lewis, 2018). Although this study focuses on the labour of journalists, we raise the relevance of feminist game studies to the evolution of digital news-making. For years, feminist game scholars have laboured to document the experiences of \#GamerGate's digital harassment survivors (Chess and Shaw, 2015; Massanari, 2017). Their work represents a pivotal archive of insight for 
researchers seeking to understand the affective and self-making labour of journalism coming under the influence(rs).

We ultimately argue that the alignment of media workers' labours of authenticity with platform authentification signals like blue check marks (1) are an assurance that safety and authenticity/transparency are the same and (2) unfairly exhort racialized and gendered subjects to disclose themselves. Everyone on the internet knows you're a dog. Now what?

\section{References}

Abidin, C. (2016). Visibility labour: Engaging with Influencers' fashion brands and \#OOTD advertorial campaigns on Instagram. Media International Australia, 161(1), 86-100.

Banet-Weiser, S. (2012). AuthenticTM: The politics of ambivalence in a brand culture. New York University Press.

Brock, A. (2015). Deeper data: a response to boyd and Crawford. Media Culture \& Society, 37(7), 1084-1088. https://doi.org/10.1177/0163443715594105

Caplan, R. (2020). Pornhub Is Just the Latest Example of the Move Toward a Verified Internet. Slate. Retrieved January 18, 2021, from https://slate.com/technology/2020/12/pornhub-verified-users-twitter.html

Chess, S., \& Shaw, A. (2015). A Conspiracy of Fishes, or, How We Learned to Stop Worrying About \#GamerGate and Embrace Hegemonic Masculinity. Journal of Broadcasting \& Electronic Media, 59(1), 208-220.

Cohen, N. S. (2015). Entrepreneurial journalism and the precarious state of media work. The South Atlantic Quarterly, 114(3), 513-533.

Duffy, B.E. (2017) (Not) getting paid to what you love: gender, social media, and aspirational work. Yale University Press.

Duffy, B. E. (2021, March 11). Meghan Markle and the long history of authenticity policing. https://www.vox.com/the-goods/22323961/meghan-markle-fakery-piers-morgan-authenticity

Gray, K. L., Buyukozturk, B., \& Hill, Z. G. (2017). Blurring the boundaries: Using Gamergate to examine "real" and symbolic violence against women in contemporary gaming culture. Sociology Compass, 11(3), e12458.

Haimson, O. L., \& Hoffmann, A. L. (2016). Constructing and enforcing "authentic" identity online: Facebook, real names and non-normative identities. First Monday. https://doi.org/10.5210/,fm.v21i6.6791

Lewis, R. (2018). Alternative influence: Broadcasting the reactionary right on YouTube. Data \& Society. https://datasociety.net/wp-content/uploads/2018/09/DS_Alternative_Influence.pdf

Lorenz, T. (2021, February 6). Journalists will learn influencing isn't easy.

https://www.niemanlab.org/2020/12/journalists-will-learn-influencing-isnt-easy/ 
Marwick, A. E. (2013). Status update: Celebrity, publicity, and branding in the social media age. Yale University Press.

Massanari, A. (2017). \#Gamergate and The Fappening: How Reddit's algorithm, governance, and culture support toxic technocultures. New Media \& Society, 19(3), 329-346.

Potter, J. (1996). Representing reality: Discourse, rhetoric and social construction. SAGE Publications Ltd.

VanDerWerff, E. (2014, September 6). Why is everybody in the video game world fighting? \#Gamergate. https://www.vox.com/2014/9/6/6111065/gamergate-explained-everybody-fighting 